\title{
Post-sintering thermal treatment of nitrogen containing pressed and sintered and PIM stainless steels
}

\author{
K. S. Hwang* and Y. W. Hsueh
}

It is known that nitrogen in the sintering atmosphere impairs the corrosion resistance but enhances the strength and hardness of sintered stainless steels. In this study, an additional postsintering thermal treatment was applied on parts that were sintered in $\mathrm{N}_{2}$ containing atmospheres and its effects on the mechanical properties and corrosion resistance were evaluated. Both pressed and sintered (P/S) 304L and powder injection moulded (PIM) 316L stainless steel compacts were examined. The results show that the $\mathrm{Cr}_{2} \mathrm{~N}$ compound was formed throughout the low density 304L compact, causing poor corrosion resistance when there was nitrogen in the sintering atmosphere. However, the high density PIM 316 L compact only contained $\mathrm{Cr}_{2} \mathrm{~N}$ at the surfaces owing to the high sintering temperature and the lack of interconnected pores. $\mathrm{This}_{\mathrm{Cr}} \mathrm{N}$ compound can be suppressed when the compact is reheated to $1100^{\circ} \mathrm{C}$ in argon and then cooled at a moderate rate of $57^{\circ} \mathrm{C} \mathrm{min}^{-1}$. With this post-sintering treatment, even the compact sintered in pure nitrogen showed satisfactory corrosion resistance results, similar to those of hydrogen sintered compacts.

Keywords: Powder injection moulding, Sintering, Stainless steel, Nitrogen atmosphere, Corrosion, Cooling rate, Chromium nitride, Powder metallurgy

\section{Introduction}

Continuous sintering furnaces and dissociated ammonia are widely used to sinter powder metal stainless steel compacts. After sintering, the compacts usually contain $0 \cdot 2-0.6 \mathrm{wt}-\%$ nitrogen, which improves the tensile strength and hardness but impairs the corrosion resistance and ductility. ${ }^{1,2}$ To alleviate the adverse effect of nitrogen on the corrosion resistance, it has been suggested that the amount of the nitrogen contained should be $<0.25$ or $0 \cdot 4 \mathrm{wt}-\% .^{3-6}$ This requires that the sintering be carried out in a temperature range where the solubility of nitrogen in the matrix is low. In addition, a fast cooling rate should also be employed to avoid the formation of chromium nitride, $\mathrm{Cr}_{2} \mathrm{~N}$, during cooling. ${ }^{4-8}$ When dissolved in the matrix and without the presence of $\mathrm{Cr}_{2} \mathrm{~N}$, the nitrogen cannot only improve the strength and hardness of austenitic stainless steels with no sacrifice in ductility but also improves the resistance in pitting corrosion. ${ }^{9,10}$ The fast cooling could, however, damage the ceramic boats, carrier trays and other conveying components that are frequently used in the pusher or walking beam furnaces owing to the thermal shock effect. Thus, it could be advantageous to perform the fast cooling separately in a low cost batch furnace, in

Department of Materials Science and Engineering, National Taiwan University, Taipei 106, Taiwan

*Corresponding author, email kshwang@ccms.ntu.edu.tw which the thermal shock problem of the stationary ceramic components is much less serious.

Because the sintered densities of powder injection moulded (PIM) stainless steels are usually much higher than those of the conventional pressed and sintered (P/S) compacts, the PIM products could have a different response to the corrosion resistance because most pores are isolated. Moreover, the reaction between the compact and the nitrogen in the sintering atmosphere could also be different owing to the lesser amount of pore surface areas. Thus, both low density P/S and high density PIM stainless steel compacts were evaluated for comparison. Four atmospheres, pure hydrogen, pure nitrogen, $85 \mathrm{~N}_{2}-15 \mathrm{H}_{2}$ and $25 \mathrm{~N}_{2}-75 \mathrm{H}_{2}$ and two different cooling rates, furnace cooled and cooling zone cooled, were employed to examine their effects on the microstructure, mechanical properties and corrosion resistance.

\section{Experimental}

The fine $316 \mathrm{~L}$ powder and coarse $304 \mathrm{~L}$ powder were used in this study to prepare the PIM and P/S specimens respectively, because they are the most widely used stainless steel powders in each process. Table 1 summarises the characteristics of these two powders. To prepare PIM specimens, the powder was mixed with a wax based binder and then injection moulded into tensile bars as per MPIF Standard no. 50. The green specimens were immersed in heptane to remove the paraffin wax during solvent debinding. The remaining 
Table 1 Characteristics of stainless steel powders used in this study

\begin{tabular}{|c|c|c|}
\hline & $316 \mathrm{~L}$ & 304L \\
\hline Average particle size, $\mu \mathrm{m}$ & $11 \cdot 2$ & $54 \cdot 0$ \\
\hline Pycnometer density, $\mathrm{g} \mathrm{cm}^{-3}$ & $7 \cdot 92$ & $7 \cdot 31$ \\
\hline Tap density, $\mathrm{g} \mathrm{cm}^{-3}$ & $4 \cdot 01$ & $4 \cdot 37$ \\
\hline Apparent density, $\mathrm{g} \mathrm{cm}^{-3}$ & - & $2 \cdot 72$ \\
\hline \multicolumn{3}{|l|}{ Chemical composition, wt-\% } \\
\hline $\mathrm{Cr}$ & $16 \cdot 45$ & $18 \cdot 17$ \\
\hline $\mathrm{Ni}$ & $12 \cdot 70$ & $10 \cdot 95$ \\
\hline Mo & 2.09 & - \\
\hline $\mathrm{Mn}$ & 0.77 & - \\
\hline $\mathrm{Si}$ & $0 \cdot 79$ & 0.85 \\
\hline $\mathrm{N}$ & 0.032 & 0.046 \\
\hline $\mathrm{O}$ & 0.50 & $0 \cdot 46$ \\
\hline $\mathrm{C}$ & 0.025 & 0.02 \\
\hline S & 0.025 & 0.027 \\
\hline Supplier & ATMIX & SCM \\
\hline
\end{tabular}

binder was thermally decomposed during the subsequent thermal debinding process by heating the specimens in hydrogen to $800^{\circ} \mathrm{C}$ at a heating rate of $1^{\circ} \mathrm{C} \mathrm{min}{ }^{-1}$. The thermally debound compacts were then sintered at $1360^{\circ} \mathrm{C}$ for $2 \mathrm{~h}$ under $\mathrm{H}_{2}, 25 \mathrm{~N}_{2}-75 \mathrm{H}_{2}, 85 \mathrm{~N}_{2}-15 \mathrm{H}_{2}$ and $\mathrm{N}_{2}$ atmospheres and then furnace cooled.

For the $\mathrm{P} / \mathrm{S}$ specimen preparation, the $304 \mathrm{~L}$ powder was mixed with $0.8 \mathrm{wt}-\%$ ethylene bis stearamide and then compacted into discs of $12.5 \mathrm{~mm}$ in diameter and $8 \mathrm{~mm}$ in thickness, with a green density of $6.72 \mathrm{~g} \mathrm{~cm}^{-3}$. The compacts were heated at $5^{\circ} \mathrm{C} \min ^{-1}$ to $550^{\circ} \mathrm{C}$ and held at that temperature for $1 \mathrm{~h}$ to remove the lubricant. The sintering was carried out at $1250^{\circ} \mathrm{C}$ under the same atmospheres as those of the PIM specimens.

To examine the effect of fast cooling on the properties of sintered stainless steels, a group of sintered specimens were reheated at the rate of $10^{\circ} \mathrm{C} \mathrm{min}{ }^{-1}$ to $1100^{\circ} \mathrm{C}$ in argon in a tube furnace and held at that temperature for $1 \mathrm{~h}$. After soaking, the specimens were pulled into the cooling zone. The average cooling rate measured at $700^{\circ} \mathrm{C}$ was $\sim 57^{\circ} \mathrm{C} \mathrm{min}{ }^{-1}$, much faster than $5^{\circ} \mathrm{C} \mathrm{min}^{-1}$ of the furnace cooling rate.

The densities of the sintered specimens were measured using the Archimedes' method. For microstructure observations, sintered tensile bars were ground, polished and etched with Fry's reagent solution. The microstructure was examined under a scanning electron microscope (SEM, XL-30, Philips, Eindhoven, The Netherlands) or a conventional optical microscope. The corrosion resistance of the sintered compacts was examined using a potentiodynamic polarisation tester for specimens immersed in a $3.5 \mathrm{wt}-\% \mathrm{NaCl}$ solution. The corrosion test was also evaluated by recording the weight losses of the specimens that were immersed in a $10 \mathrm{wt}-\% \mathrm{HCl}$ solution at room temperature for $24 \mathrm{~h}$. To correlate the corrosion behaviour with the amount of nitrogen, the nitrogen content was measured using a N/O analyser (CS-136, LECO Corp., St Joseph, MI, USA). To understand the effect of nitrogen on the corrosion resistance and mechanical properties of sintered compacts, the phase diagrams of $316 \mathrm{~L}-\mathrm{N}$ and $304 \mathrm{~L}-\mathrm{N}$ were established using the Thermo-Calc programme and a TCFE3 database (Thermo-Calc Software, Stockholm, Sweden).

\section{Results \\ PIM 316L}

Because the contents of $\mathrm{C}, \mathrm{N}$ and $\mathrm{O}$ are critical to the corrosion resistance of stainless steels, particularly because the PIM specimens contained $\sim 35$ vol. $-\%$ binders that need to be removed during debinding, the amounts of these elements were examined closely. Table 2 shows that the contents of the nitrogen and oxygen did not change much after thermal debinding. However, the amount of carbon in the PIM $316 \mathrm{~L}$ specimen increased from the original 0.025 to $0.057 \mathrm{wt}-\%$, much higher than the desired $0.03 \mathrm{wt}-\%$ maximum. This suggests that some carbon was left as soot on powder surfaces or was dissolved in the matrix after debinding. Fortunately, the amount of carbon decreased significantly after sintering and met the specification. The oxygen content also decreased after sintering. Table 2 also shows that the nitrogen content in the as sintered specimen increased with increasing amount of nitrogen in the sintering atmosphere. These changes in nitrogen content are in agreement with those predicted by the phase diagram. ${ }^{3,4}$ When reheated and cooling zone cooled in argon, some nitrogen was desorbed. This was also expected because there was no nitrogen in the atmosphere.

Table 3 shows the effect of nitrogen content in the atmosphere on the density, hardness, tensile strength and elongation of sintered PIM 316L compacts. The specimen sintered in pure hydrogen had a density of $7 \cdot 76 \mathrm{~g} \mathrm{~cm}^{-3}$, a hardness of $60 \mathrm{HRB}$, an ultimate strength of $473 \mathrm{MPa}$ and an elongation of $58 \%$. As the nitrogen content in the sintering atmosphere increased, the density and elongation decreased, while the hardness and strength increased. When the specimen was sintered in pure nitrogen, it had a hardness of $83 \mathrm{HRB}$, an ultimate strength of $577 \mathrm{MPa}$ and an elongation of $25 \%$. These changes were mainly caused by the amount of nitrogen dissolved in the compact and by the formation of the $\mathrm{Cr}_{2} \mathrm{~N}$ compound, which was formed during cooling. ${ }^{6}$ When these specimens were reheated to $1100^{\circ} \mathrm{C}$ and cooled in the cooling zone, the hardness decreased, while the elongation increased. This was mainly attributed to the loss of nitrogen in the specimen and the inhibition of the $\mathrm{Cr}_{2} \mathrm{~N}$ formation.

Table 2 Changes of carbon, oxygen and nitrogen in PIM 316L specimens throughout process, wt-\%

\begin{tabular}{|c|c|c|c|c|c|c|}
\hline & \multirow{2}{*}{$\begin{array}{l}\text { As received } \\
\text { powder }\end{array}$} & \multirow{2}{*}{$\begin{array}{l}\text { After thermal } \\
\text { debinding }\end{array}$} & \multicolumn{4}{|l|}{ After sintering } \\
\hline & & & $\mathrm{H}_{2} \mathrm{AS} / \mathrm{R} \& \mathrm{CC}^{*}$ & $25 \mathrm{~N}_{2}-75 \mathrm{H}_{2}$ AS/R\&CC* & $85 \mathrm{~N}_{2}-15 \mathrm{H}_{2} \mathrm{AS} / \mathrm{R} \& \mathrm{CC}^{*}$ & $\mathrm{~N}_{2}$ AS/R\&CC* \\
\hline $\mathrm{N}$ & 0.032 & 0.031 & $0.022 / 0.021$ & $0 \cdot 224 / 0 \cdot 151$ & $0.272 / 0.255$ & $0.329 / 0.271$ \\
\hline C & 0.025 & 0.057 & $0.012 / 0.009$ & $0 \cdot 017 / 0 \cdot 014$ & $0.024 / 0 \cdot 025$ & $0.031 / 0.028$ \\
\hline 0 & 0.500 & 0.495 & $0.105 / 0.092$ & $0 \cdot 221 / 0 \cdot 190$ & $0.331 / 0 \cdot 242$ & $0.392 / 0.275$ \\
\hline
\end{tabular}

*AS: as sintered and furnace cooled; R\&CC: reheated and cooling zone cooled. 




1 Weight loss of specimen that had been immersed in $10 \mathrm{wt}-\% \mathrm{HCl}$ increases with increasing nitrogen content in atmosphere and decreasing cooling rate

To compare the corrosion resistances, the as sintered specimens were immersed in $10 \mathrm{wt}-\% \mathrm{HCl}$ solution for $24 \mathrm{~h}$. Figure 1 shows that the weight loss increased with increasing nitrogen content in the sintering atmosphere. The polarisation curves, as shown in Fig. 2, also indicated that no passivation regime was present when specimens were sintered in the $\mathrm{N}_{2}$ containing atmospheres. However, when the specimens were reheated in argon to $1100^{\circ} \mathrm{C}$ and then fast cooled in the cooling zone, the weight loss was significantly reduced. The polarisation curves also showed much improved characteristics with passivation regimes and higher corrosion potentials, even for compacts sintered in the pure nitrogen atmosphere.

When the surfaces of the PIM 316L specimens were examined under the SEM, a second phase was seen, as shown in Fig. 3, in the tensile bars sintered in nitrogen containing atmospheres. This seemed to be in contradiction to those reported in previous studies, which indicated that no nitrides were observed when the nitrogen content was $<0.4 \mathrm{wt}-\%$. When the cross-section was examined, the second phase had a lamellar structure, as shown in Fig. 4, and was only found at the surfaces. This suggested that the nitrogen content at the surfaces was greater than $0.4 \mathrm{wt}-\%$ and the $\mathrm{Cr}_{2} \mathrm{~N}$ formation could cause local depletion of $\mathrm{Cr}$ and thus the poor corrosion resistance despite the fact that the total amount of nitrogen is $<0.4 \%$ or even $0.25 \%$. Figure 4 also shows that the depth of the lamellae increased with increasing nitrogen content in the sintering atmosphere. These lamellae were identified by the X-ray diffraction pattern as $\mathrm{Cr}_{2} \mathrm{~N}$. No lamellae were found in the centre regions of any specimens. These results indicated that some extra nitrogen was absorbed, particularly at the

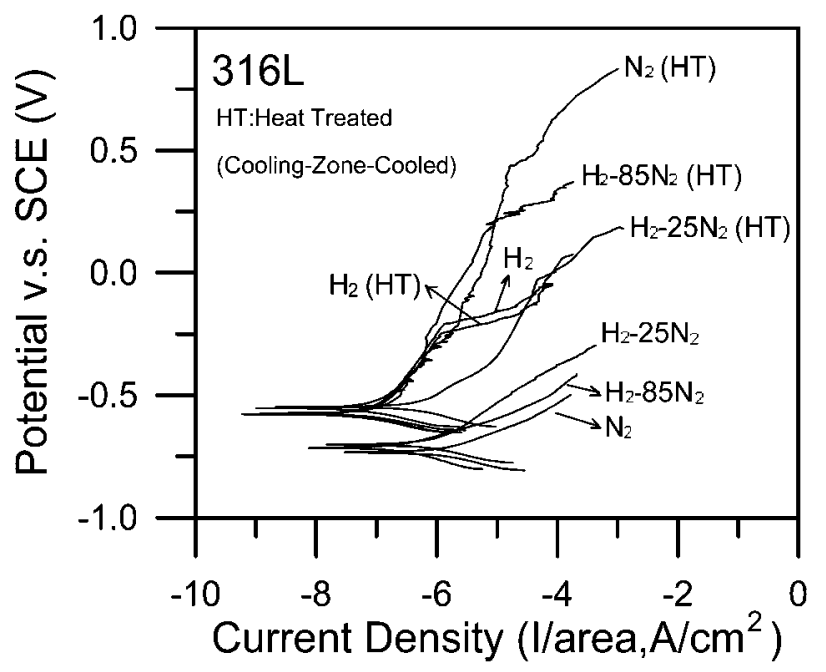

2 Potentiodynamic scans of specimens that were sintered in atmospheres containing different amounts of nitrogen and cooled at different cooling rates

surfaces, during the slow furnace cooling. As the specimen was further cooled to lower temperatures, the extra nitrogen that was absorbed became oversaturated and formed $\mathrm{Cr}_{2} \mathrm{~N}$ compounds. In contrast, no nitrogen was picked up in the centre region during cooling because most pores had been closed after sintering.

When these specimens were reheated to $1100^{\circ} \mathrm{C}$ and cooled in the cooling zone, no lamellar structures were found, either at the surface or in the core region, even in those specimens sintered in pure nitrogen, as shown in Fig. 5. The X-ray diffraction pattern also confirmed that no $\mathrm{Cr}_{2} \mathrm{~N}$ was present in any fast cooled specimens. This result indicated that the $\mathrm{Cr}_{2} \mathrm{~N}$ at the surfaces, which was present in the as sintered and furnace cooled specimens, dissolved back into the matrix during soaking at $1100^{\circ} \mathrm{C}$ and remained in solution in the matrix during the fast cooling. Thus, the formation of $\mathrm{Cr}_{2} \mathrm{~N}$ must have two prerequisites. The first one is that enough nitrogen must be absorbed in the temperature range where the solubility of nitrogen is high. The second one is that the specimens must be cooled at a slow enough speed so that the oversaturated nitrogen has enough time to form $\mathrm{Cr}_{2} \mathrm{~N}$ at low temperatures.

\section{P/S 304L}

Table 4 shows that the contents of the nitrogen and oxygen in the P/S 304L compacts did not change much after thermal debinding; however, the amount of carbon increased from the original 0.020 to $0.063 \mathrm{wt}-\%$. After sintering, the amount of carbon decreased significantly and was close to $0.03 \mathrm{wt}-\%$. The contents of carbon, oxygen and nitrogen were all higher than those of the PIM 316L specimens.

Table 3 Effect of nitrogen content in sintering atmosphere on density, hardness, strength and elongation of PIM 316L sintered compacts

\begin{tabular}{|c|c|c|c|c|}
\hline & $\mathrm{H}_{2}$ AS/R\&CC* & $25 \mathrm{~N}_{2}-75 \mathrm{H}_{2}$ AS/R\&CC* & $85 \mathrm{~N}_{2}-15 \mathrm{H}_{2} \mathrm{AS} / \mathrm{R} \& \mathrm{CC}^{*}$ & $\mathrm{~N}_{2}$ AS/R\&CC* \\
\hline Hardness, HRB & $60 / 60$ & $73 / 68$ & $78 / 75$ & $83 / 79$ \\
\hline Tensile strength, MPa & $473 / 458$ & $535 / 540$ & $565 / 565$ & $577 / 585$ \\
\hline Elongation, \% & $58 / 59$ & $31 / 37$ & $28 / 33$ & $25 / 29$ \\
\hline Density, $\mathrm{g} \mathrm{cm}^{-3}$ & $7 \cdot 76$ & $7 \cdot 65$ & $7 \cdot 60$ & $7 \cdot 56$ \\
\hline
\end{tabular}

*AS: as sintered and furnace cooled; R\&CC: reheated and cooling zone cooled. 


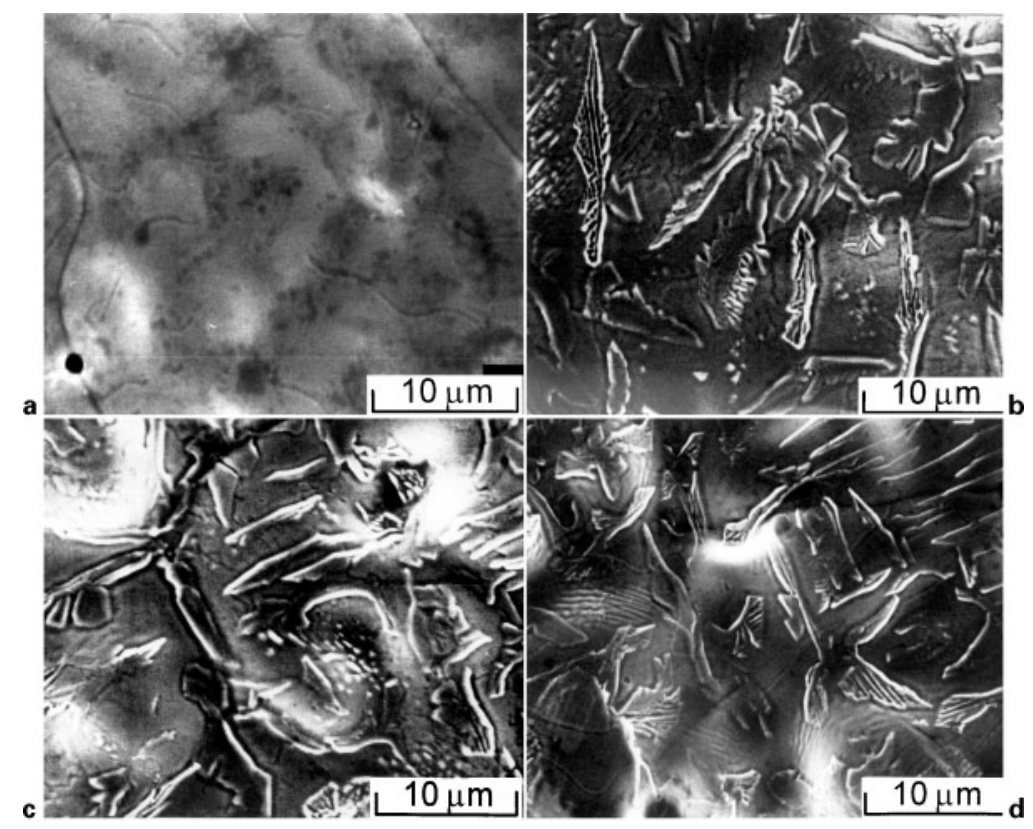

a $\mathrm{H}_{2} ; b \mathrm{~N}_{2}-75 \mathrm{H}_{2} ; c \mathrm{~N}_{2}-15 \mathrm{H}_{2} ; d \mathrm{~N}_{2}$

3 Surfaces of furnace cooled specimens show that amount of second phase increases with increasing nitrogen content in sintering atmosphere

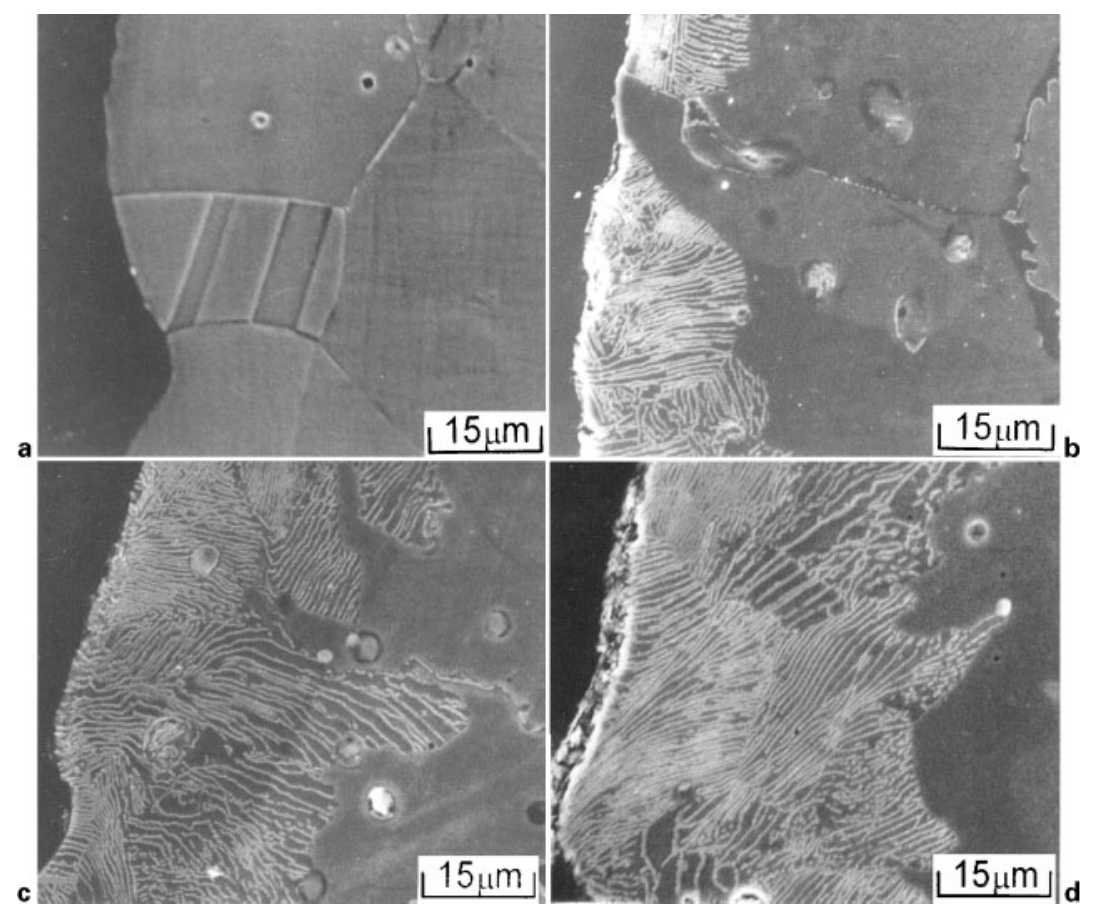

a $\mathrm{H}_{2} ; b \mathrm{~N}_{2}-75 \mathrm{H}_{2} ; c \mathrm{~N}_{2}-15 \mathrm{H}_{2} ; d \mathrm{~N}_{2}$

4 Microstructure of cross-section shows that depth of lamella structures increases with increasing nitrogen content in sintering atmosphere

Table 4 Changes of carbon, oxygen and nitrogen in P/S 304L specimens throughout process, wt-\%

\begin{tabular}{|c|c|c|c|c|c|c|}
\hline & \multirow[b]{2}{*}{ As received powder } & \multirow[b]{2}{*}{ After thermal debinding } & \multicolumn{4}{|l|}{ After sintering } \\
\hline & & & $\mathrm{H}_{2}$ AS/R\&CC* & $\mathrm{N}_{2}-75 \mathrm{H}_{2}$ AS/R\&CC* & $\mathrm{N}_{2}-15 \mathrm{H}_{2}$ AS/R\&CC* & $\mathrm{N}_{2}$ AS/R\&CC* \\
\hline $\mathrm{N}$ & 0.043 & 0.042 & $0.028 / 0.027$ & $0.545 / 0 \cdot 478$ & $0.540 / 0 \cdot 482$ & $0.572 / 0.531$ \\
\hline C & 0.020 & 0.063 & $0.026 / 0.024$ & $0.030 / 0.029$ & $0.038 / 0.037$ & $0.037 / 0.036$ \\
\hline 0 & 0.424 & 0.418 & $0 \cdot 310 / 0 \cdot 305$ & $0.442 / 0 \cdot 371$ & $0 \cdot 490 / 0 \cdot 426$ & $0 \cdot 483 / 0 \cdot 410$ \\
\hline
\end{tabular}

*AS: as sintered and furnace cooled; R\&CC: reheated and cooling zone cooled. 


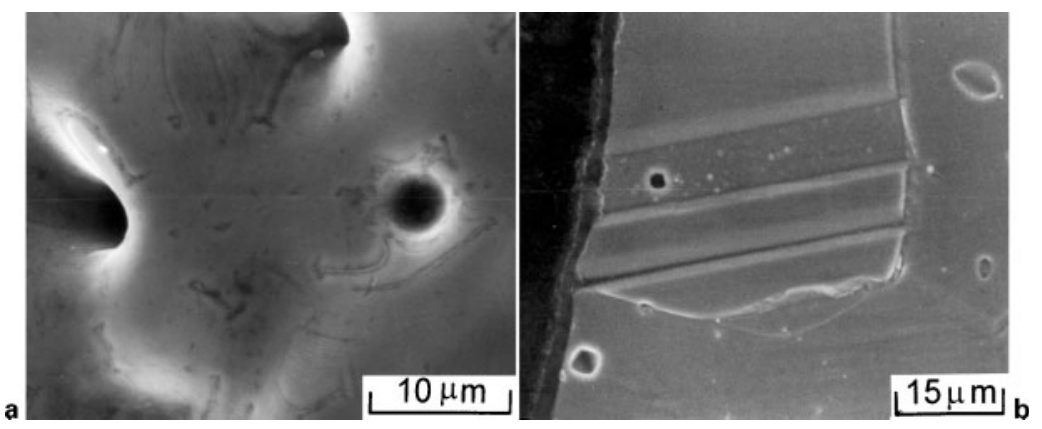

5 a surface morphology and $b$ cross-section of compact sintered in pure nitrogen show no lamella structures when compact is reheated to $1100^{\circ} \mathrm{C}$ in argon and cooled in cooling zone

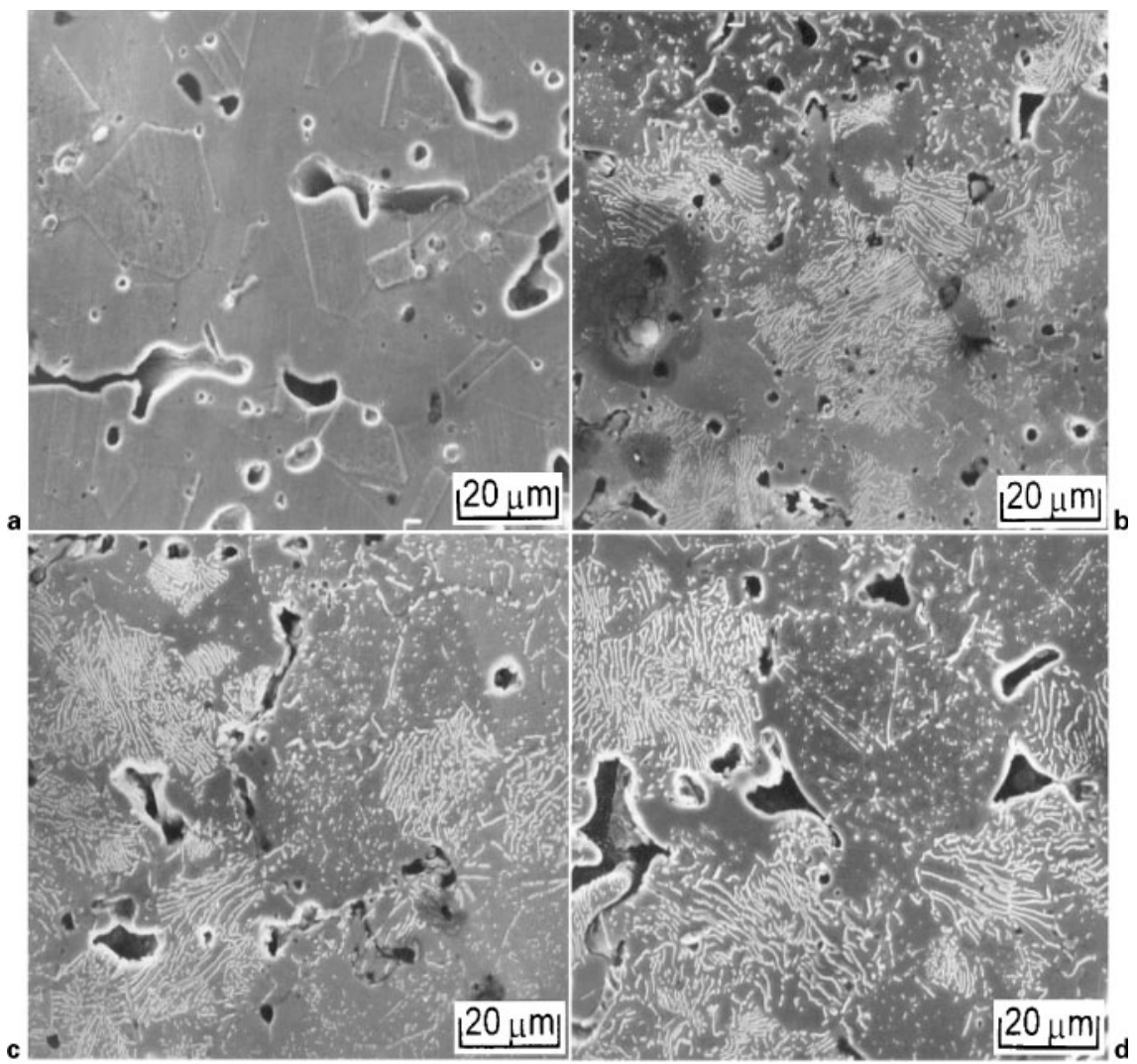

a $\mathrm{H}_{2} ; b \mathrm{~N}_{2}-75 \mathrm{H}_{2} ; c \mathrm{~N}_{2}-15 \mathrm{H}_{2} ; d \mathrm{~N}_{2}$

6 Lamellar structures can be found in centre region of $304 \mathrm{~L}$ compacts when nitrogen is contained in sintering atmosphere

Table 5 shows that the sintered density and hardness of the P/S $304 \mathrm{~L}$ compacts were related to the nitrogen content in the sintering atmosphere in a way similar to the case of the PIM 316L compacts. However, big differences were noticed in the microstructure. As shown in Fig. 6, the centre region of the $304 \mathrm{~L}$ compact contained lamellar structures, while the $316 \mathrm{~L}$ PIM specimen did not. The main reason was that, as shown in Fig. 7, the solubility of nitrogen in the 304L stainless steels is much higher at $1250^{\circ} \mathrm{C}$ than that of $316 \mathrm{~L}$ at $1360^{\circ} \mathrm{C}$. This was confirmed by Table 4 , which shows that the $304 \mathrm{~L}$ contained more nitrogen than did the 316L. Moreover, because coarser powders and lower sintering temperatures were used on the P/S $304 \mathrm{~L}$, the density thus attained was lower and more interconnected pores were available for the nitrogen in the sintering atmosphere to penetrate into the centre region of the compact. Therefore, more nitrogen was contained in the 304L specimen, more $\mathrm{Cr}_{2} \mathrm{~N}$ was formed after furnace cooling and little difference was found between the

Table 5 Effect of nitrogen content in sintering atmosphere on density, hardness, strength and elongation of P/S 304L sintered compacts

\begin{tabular}{lllll}
\hline & $\mathrm{H}_{2}$ AS/R\&CC* & $\mathrm{N}_{2}-\mathbf{7 5} \mathrm{H}_{2}$ AS/R\&CC* & $\mathrm{N}_{2}-\mathbf{1 5 H}_{2}$ AS/R\&CC* & $\mathrm{N}_{2}$ AS/R\&CC* \\
\hline Hardness, HRB & $38 / 37$ & $67 / 65$ & $74 / 70$ & $80 / 75$ \\
Density, $\mathrm{g} \mathrm{cm}^{-3}$ & $7 \cdot 01$ & 6.99 & 6.98 & 6.98 \\
\hline
\end{tabular}

*AS: as sintered and furnace cooled; R\&CC: reheated and cooling zone cooled. 

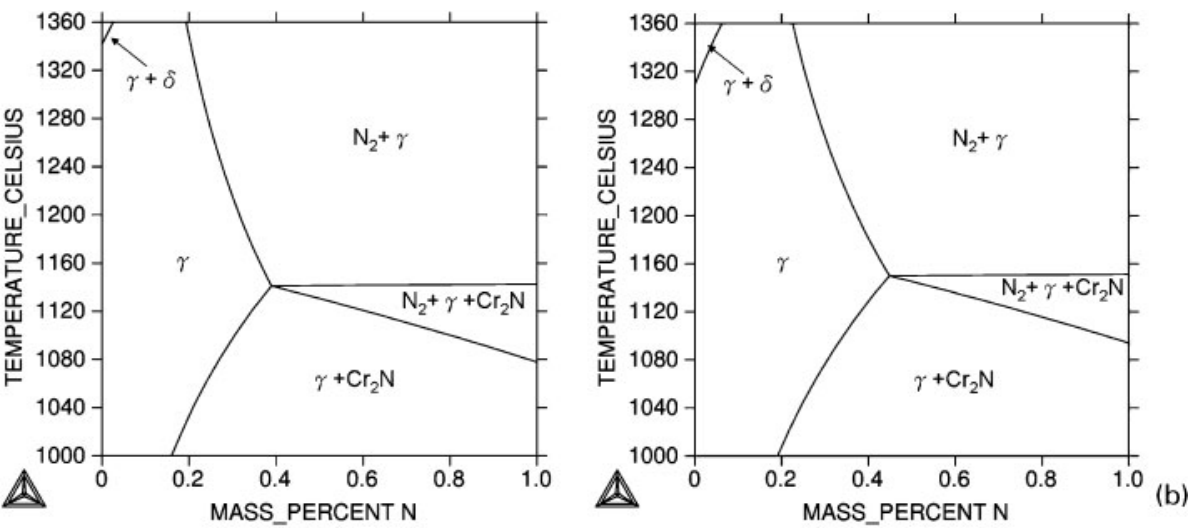

7 Phase diagrams of $a 316 \mathrm{~L}-\mathrm{N}$ and $b 304 \mathrm{~L}-\mathrm{N}$, calculated from compositions listed in Table 1 using Thermo-Calc programme, show that solubility of nitrogen in stainless steels is higher at $1250^{\circ} \mathrm{C}$ than at $1360^{\circ} \mathrm{C}$

microstructures at the surface and at the core region. Nonetheless, when sintered 304L specimens were reheated in argon to $1100^{\circ} \mathrm{C}$ and cooled in the cooling zone, all lamellar structures disappeared, just as observed in PIM 316L compacts. The nitrogen content in the specimen also decreased slightly, as shown in Table 4.

The results of the weight loss experiment and the polarisation test, as shown in Figs. 8 and 9 respectively, demonstrate that much more weight loss and lower corrosion potential were obtained than in the PIM 316L compact. The effects of nitrogen on P/S 304L compacts were similar to those of the PIM 316L compacts, i.e. when the nitrogen content in the specimen was low and when fast cooling was employed, the corrosion resistance improved.

\section{Discussion}

The results given above show that the hardness of sintered PIM 316L or P/S 304L increases with increasing nitrogen content in the sintering atmosphere. This increase in hardness could be attributed to the solid solutioning effect and/or the formation of the $\mathrm{Cr}_{2} \mathrm{~N}$ lamellae. The solid solutioning effect can be demonstrated by comparing the hardness of fast cooled specimens, as shown in Fig. 10. Because there are no



8 Weight loss of specimen that was immersed in $10 \mathrm{wt}$ \% $\mathrm{HCl}$ decreases significantly after fast cooling treatment



9 Potentiodynamic scans of 304L specimens that were sintered in atmospheres containing different amounts of nitrogen and cooled at different cooling rates

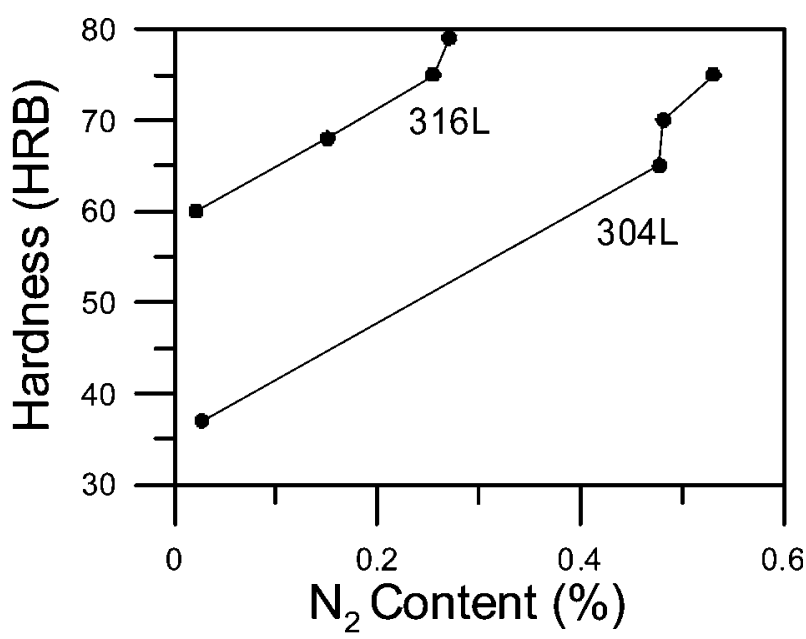

10 Hardness of fast cooled P/S 304L and PIM 316L specimens increases with increasing nitrogen content

lamellae present and the density decreases with increasing nitrogen content, the hardness increase must be mainly caused by the solutioning of nitrogen. The lamellar $\mathrm{Cr}_{2} \mathrm{~N}$, however, also contributes slightly to the increase in hardness, as the furnace cooled $316 \mathrm{~L}$ that contained $\mathrm{Cr}_{2} \mathrm{~N}$ only at the surfaces is harder than that 
of the fast cooled specimen, but the tensile strengths of the two specimens are similar.

Because the $\mathrm{Cr}_{2} \mathrm{~N}$ impairs the corrosion resistance of stainless steels, it is better to keep the nitrogen content low at the beginning. Previous studies reported that the solubility limits for nitrogen increase with increasing chromium content and the amount of nitrogen in the atmosphere. $^{4,5,8}$ It is also generally accepted that the nitrogen solubility increases first with increasing temperature from room temperature to $\sim 1120^{\circ} \mathrm{C}$ and then decreases with further increasing temperature. Such a trend is in agreement with the equilibrium curves, which were calculated in this study using the Thermo-Calc programme. As shown in Fig. 7, the curves indicate that the maximum nitrogen solubilities of $304 \mathrm{~L}$ and $316 \mathrm{~L}$ are $0.451 \mathrm{wt}-\%$ at $1152^{\circ} \mathrm{C}$ and $0.390 \mathrm{wt}-\%$ at $1142^{\circ} \mathrm{C}$ respectively. Thus, as sintered stainless steels are cooled from 1360 or $1250^{\circ} \mathrm{C}$, absorption of nitrogen occurs. After the specimens pass the temperature at which the maximum solubility exists, $\mathrm{Cr}_{2} \mathrm{~N}$ then forms, particularly above $700^{\circ} \mathrm{C}$, below which the reaction rate is too slow.

The results given in the previous section show that the $\mathrm{Cr}_{2} \mathrm{~N}$ compound does not much improve the mechanical properties but does impair significantly the corrosion resistance. Thus, previous studies suggested that the maximum amount of nitrogen in sintered stainless steels should be controlled to $<0 \cdot 4 \mathrm{wt}-\%$ or even $0.25 \mathrm{wt}-\%{ }^{3-6}$ This, however, does not guarantee that $\mathrm{Cr}_{2} \mathrm{~N}$ will not form as shown at the surface of the PIM $316 \mathrm{~L}$ specimen sintered in dissociated ammonia, which contained a total amount of $0 \cdot 224 \mathrm{wt}-\%$ nitrogen. Therefore, fast cooling must be employed in order to prevent the compound from forming. This, however, is difficult in continuous high temperature furnaces, because the ceramic plates, boats and conveying components are prone to cracking or distortion when fast cooling is employed. Thus, an alternative process is to perform a post-sintering treatment by reheating sintered parts in a low cost batch furnace at a low temperature of $\sim 1150^{\circ} \mathrm{C}$ to dissolve the $\mathrm{Cr}_{2} \mathrm{~N}$, which forms at the cooling stage of the sintering cycle, back into the matrix again, and then followed by fast cooling to suppress the $\mathrm{Cr}_{2} \mathrm{~N}$ formation. Such a post-sintering treatment could be carried out in either argon or vacuum so that the total amount of nitrogen can be reduced. The parts can be placed or stacked on metal or ceramic plates without worrying the sinter bonding between the contacting components owing to the low solutioning temperature. The distortion or even cracking of the setter plates is not a big concern either, because the plates are not movable parts and are reusable. The products thus obtained contain high amounts of solutioned nitrogen, which contributes to improved mechanical properties without deteriorating the corrosion resistance. Using an approximate rate of $57^{\circ} \mathrm{C} \mathrm{min}{ }^{-1}$, the $\mathrm{Cr}_{2} \mathrm{~N}$ formation was suppressed. This cooling rate is slower than the critical cooling rates suggested by Sands et al. and Frisk et al. ${ }^{7,8}$ This difference could be attributed to the slightly lower amount of nitrogen contained in our specimens. These results also suggest that the critical cooling rate depends on the sintering temperature, nitrogen content in the sintering atmosphere and the chemistry of the material.

\section{Conclusions}

The effects of nitrogen in the sintering atmosphere on both PIM 316L and P/S 304L stainless steel compacts were examined in this study. When PIM 316L specimens were sintered at $1360^{\circ} \mathrm{C}, \sim 0 \cdot 2 \mathrm{wt}-\%$ nitrogen was dissolved. But some extra nitrogen was absorbed during cooling owing to the increase in the nitrogen solubility until $\sim 1150^{\circ} \mathrm{C}$. As the temperature further cooled and the nitrogen solubility decreased, lamellar $\mathrm{Cr}_{2} \mathrm{~N}$ compound formed at the surfaces of the specimen. No lamellae were found in the centre of the compact because most pores became isolated after sintering and the nitrogen could not permeate into the core region of the specimen. When specimens were reheated and then cooled in the cooling zone in argon with a cooling rate of $\sim 57^{\circ} \mathrm{C} \mathrm{m^{-1 }}$, no $\mathrm{Cr}_{2} \mathrm{~N}$ lamellar structures were found, even in those compacts sintered in pure nitrogen.

For P/S 304L compacts, the lamellae structures can be found all over the specimen because more nitrogen could be dissolved in the compact at $1250^{\circ} \mathrm{C}$, compared with $1360^{\circ} \mathrm{C}$ used for PIM $316 \mathrm{~L}$ specimens, and more interconnected pores were contained in the compact. When these compacts were reheated to $1100^{\circ} \mathrm{C}$ and then cooled in the cooling zone, all $\mathrm{Cr}_{2} \mathrm{~N}$ lamella structure disappeared. These results suggest that the cost effective nitrogen containing atmosphere can still be used in the high temperature continuous furnace using slow cooling to prevent damages of ceramic components caused by the thermal shock effect. However, the sintered parts should be reheated to $\sim 1150^{\circ} \mathrm{C}$ and subsequently fast cooled, which can be carried out in a low cost batch furnace. With such a post-sintering treatment, the corrosion resistance, as demonstrated by the weight loss data and potentiodynamic polarisation curves of both 304L and 316L compacts, were much improved, even for those sintered in pure nitrogen.

\section{References}

1. 'Materials standards for P/M structural parts', MPIF Standards 35, 2003 edn, MPIF, Princeton, NJ, USA, 52-53.

2. J. Rawers, F. Croydon, R. Krabbe and N. Duttlinger: Int. J. Powder Metall., 1996, 32, (4), 319-322.

3. M. Svilar and H. D. Ambs: Prog. Powder Metall., 1987, 43, 163 180

4. M. A. Pao and E. Klar: Prog. Powder Metall., 1984, 39, 431-443.

5. H. S. Nayar, R. M. German and W. R. Johnson: Prog. Powder Metall., 1981, 37, 255-265.

6. G. Lei, R. M. German and H. S. Nayar: Powder Metall. Int., 1983, 15, (2), 70-76

7. R. L. Sands, G. F. Bidmead and D. A. Oliver: Mod. Dev. Powder Metall., 1966, 2, 73-83.

8. K. Frisk, A. Johansson and C. Lindberg: Adv. Powder Metall. Part. Mater., 1992, 3, 167-179.

9. Y. S. Lim, J. S. Kim, S. J. Ahn, H. S. Kwon and Y. Katada: Corros. Sci., 2001, 43, 53-68.

10. R. Tandon, J. W. Simmons, B. S. Covino, Jr and J. H. Russel: Int. J. Powder Metall., 1988, 34, (8), 47-54. 